Article

\title{
Recreation in Different Forest Settings: A Scene Preference Study
}

\section{Louise Eriksson $^{1, *}$, Annika M. Nordlund ${ }^{2}$, Olof Olsson ${ }^{1}$ and Kerstin Westin ${ }^{1}$}

1 Department of Geography and Economic History, Umeå University, SE-901 87 Umeå, Sweden; E-Mails: olof.olsson@geography.umu.se (O.O.); kerstin.westin@geography.umu.se (K.W.)

2 Department of Psychology, Umeå University, SE-901 87 Umeå, Sweden;

E-Mail: annika.nordlund@psy.umu.se

* Author to whom correspondence should be addressed; E-Mail: louise.eriksson@geography.umu.se; Tel.: +46-90-7865000; Fax: +46-90-7866359.

Received: 19 June 2012; in revised form: 17 September 2012 / Accepted: 20 September 2012 /

Published: 18 October 2012

\begin{abstract}
Recreation activity preferences in forest settings were explored in a scene preference study. The importance of type of human intervention and the level of biodiversity for preference and intention to engage in recreation activities were examined in a sample of forestry and social science students in Sweden. Results showed that forestry students displayed an almost equally strong preference for natural-looking scenes as for scenes with traces of recreation (e.g., paths), whereas social science students preferred recreational scenes the most. Least preferred were scenes with traces of forest management. Different forest settings were furthermore preferred for different recreation activities. Recreational settings were favored for walking and going on outings, and natural-looking settings were more appreciated for picking berries or mushrooms. Respondents displayed a stronger intention to study plants and animals in high biodiversity settings and the intention to exercise was stronger in low biodiversity settings. Implications for future land use planning and forest management are discussed.
\end{abstract}

Keywords: forest scene preference; recreation activities; human intervention; biodiversity; forest experience 


\section{Introduction}

Forests hold a multitude of values. For example, the economic value of the production of timber and biomass is important not only from forest owners' perspective, but also for employment, trade, and the national economy. Forests are also important for environmental reasons such as biodiversity, the protection of plants and animals, and as a carbon sink. More recently, the social values have been highlighted, and the importance of forests for recreation, restoration and experiencing nature are recognized. A range of different leisure activities occur in a forest setting, for example: walking, running, riding, biking, going on outings, and picking berries and mushrooms, but also hunting, fishing in streams, and camping [1-3]. Spending time in natural environments such as forests positively influences humans' mental and physical health [4].

Previous studies have found that individual characteristics such as age, dog ownership, and distance are important for frequency of visits to natural settings [1,5-7]. From a landscape planning perspective, however, there is also a need to understand what type of forests people prefer for different recreation activities [8,9]. In landscape preference research, setting characteristics (e.g., density, tree composition and age) important for preference (i.e., liking), or scenic beauty, are explicitly examined [10-12]. However, assessments differ depending on whether the setting is evaluated in terms of liking a setting or in order to conduct a specific activity in that setting [3,13-15], indicating a need to distinguish between preference on the one hand and intentions to visit a setting on the other [16]. If this distinction is noted, landscape preference research can be seen as a viable point of departure when examining forest-setting preferences in relation to recreation activities.

The aim of this study was to examine visual preference and intention to engage in recreation activities in different forest settings among those with a higher expertise in relation to forest issues as compared to more novice individuals. This scene preference study was conducted in Sweden, where the right of public access is very generous, allowing the public to visit forests for various activities [17]. We examined five recreation activities, which are typically included in the Swedish general public's rights in forests: walking, going on outings (e.g., picnic), exercising, picking berries or mushrooms, and studying plants and animals. Some of these activities, such as walking in the forest, are very common in Sweden whereas fewer people study plants and animals [18]. More specifically, this preference study measured factors that could influence preference and intention to visit forests: landscape components including traces of forest recreation, forest management, and level of biodiversity; as well as individual characteristics, such as the level of experience in a forest setting. Landscape preference is commonly examined by utilizing different types of visual stimuli, such as photos, manipulated images, or observations in the field $[15,19,20]$. Notably, the advantages of using visual research methods have also been noted in recreational research [21].

\section{Forest Preference and Recreation Activities}

Reviews of forest preference studies [22-24] demonstrate that people tend to prefer forest scenes that exhibit a high number of large trees of different ages and species with an understory composed of low, sparse ground vegetation. Dead trees, or slash, commonly elicit more negative preference ratings. In line with these results, field/forest scenes that exhibit higher visibility and physical accessibility 
tend to have higher preference ratings [25]. Hence, human activity and management methods, as well as the level of biodiversity, influence the appearance of forests and seem to be relevant to preference. In addition, people's experience and knowledge of forest and forest management influence their preferences for forests scenes [26]. Hence, experts such as people with a forest education, are likely to have different perceptions of what forests should look like and how they should be managed, than non-experts.

\subsection{Human Intervention}

The landscape preference literature suggests that human interventions have an impact on preference [27]. Studies of forest management strategies have generally shown that more natural-appearing forests are preferred whereas those with obvious signs of forest management, such as clear cuts, are not [23]. It is uncertain, however, how less obvious signs of forest management influence preference. In one study, re-growth on a clear cut and partial retention was rated somewhere in-between natural forests and clear cuts [28], although forests with lower density (e.g., as a result of thinning) have been found to increase preference ratings $[23,24]$. Managed forests with smaller paths or trails may furthermore be preferred over completely natural forests [29]. In relation to recreational activities, Shelby et al. [14] demonstrated that old growth (cf. natural forest) was perceived to be the most acceptable both for hiking and camping, whereas clear cuts and other management strategies were less acceptable. In line with this result, Gan et al. [13] demonstrated higher preference ratings for more natural forests compared to different forest treatments, although treatments that created more open space were valued most highly for hiking, walking, and cycling at one experimental site. Moreover, a review of forest preference studies in Norway, Sweden, and Finland, revealed that moderately prepared forest paths were valued for walking [22]. With regard to different recreational groups, Roovers et al. [2] showed that joggers particularly preferred wide forest paths to narrow ones. Together these studies show that certain signs of human intervention, such as clear cuts, often have a negative influence on preference while interventions, such as prepared paths or trails, can have a positive impact. Parallels may be drawn to the distinction between human induced transformation of the landscape (e.g., a water reservoir) and signs of human presence (e.g., houses) as two types of visually evident human intervention important for landscape preference [30].

Undoubtedly, more visually appealing interventions are likely to be more appreciated, although the rationale behind the intervention may also play a role. For example, when humans have altered the landscape for utilitarian purposes (e.g., for timber production), preference may be negatively influenced. This reasoning is in line with studies revealing that those with a more utilitarian worldview have a less negative view of clear cuts than others [28]. Studies have furthermore revealed that if visitors are provided with a justification for management actions such as fencing, preference can increase [31]. Previous studies have shown that interventions that convey respect for the landscape can increase preference [32]; therefore, managed forests and recreation paths may be seen as an outcome of care for rather than a mastering of nature, and facilitate higher preference for the scene. Although the effect of human interventions on the intention to engage in some activities, such as walking, may be comparable to preference, there are indications that different settings may be preferred for different activities [13]. 


\subsection{Biodiversity}

A rich diversity in plant and animal life is an important environmental goal in many countries [33-35]. To accommodate both environmental and social values in the forest, it is essential to understand the relation between biodiversity and preference. People have been found to prefer low biodiversity scenes of open areas with groups of bushes and trees rather than high biodiversity scenes of dense vegetation, leading several researchers to suggest that there is a conflict between biodiversity and visual esthetics and that people would be less likely to visit low biodiversity settings [36-38]. For example, Gundersen and Frivold [39] found that a respondent sample in Norway rated forest scenes with dead wood lower compared to scenes with little or no visible dead wood, indicating that people may prefer forests with lower levels of biodiversity. However, access to ecological information about the forest scene resulted in a higher rating of the scenes with dead wood. In contrast, Williams and Cary [40] found only minor differences between natural scenes with different levels of biodiversity and there was no apparent correlation between people's preference and expert rated levels of biodiversity. Moreover, studies of different natural scenes, such a garden landscapes, rivers, and brownfields, have demonstrated that high biodiversity scenes (rated by experts) tend to be more preferred than low biodiversity scenes [41-43]. Together these studies suggest that only when people are aware of the biodiversity level they are likely to display higher preference for high biodiversity settings.

\subsection{Forest Experience}

In general, studies demonstrate similarities in landscape preference in different societal groups, though differences have most notably been found between experts and non-experts [26,44]. In relation to forest scenes, greater differences between sub-groups have commonly been revealed for scenes perceived as less beautiful compared to more beautiful ones [28,45]. Several reviews demonstrate that foresters (i.e., those with a forest education or professional foresters) differ in preference compared to non-foresters (e.g., other professional groups or the general public), although mainly in relation to forests showing clear signs of forest management [22-24]. For example, foresters have been found to prefer intensive treatments (e.g., clear cuts) more than others $[12,46]$. These differences have been explained by referring to the different values and attitudes held by these groups. Kearney and Bradley [28] demonstrated that foresters' stronger commodity/utilitarian perspective on forests could explain the difference in preference between foresters and environmentalists concerning the more intensive treatments. In studies of forest recreation activities, however, comparisons have commonly been made between different recreational groups rather than between groups with different levels of setting experience [3].

\subsection{The Present Study}

To improve the understanding of activity preferences in forests, the present study examined both preference (i.e., liking) and a range of intended activities (walking, outings (e.g., picnic), picking berries or mushrooms, exercising, and studying plants and animals) in different forest settings in Sweden. Although a stated intention to do something does not mean that the activity will be carried out, 
a strong correlation is generally found between intentions and behaviors [47]. More specifically, the effects of (1) human intervention (i.e., natural-looking, with traces of recreation, and with traces of forest management); (2) level of biodiversity (i.e., low versus high) and (3) forest experience (i.e., forestry and social science students) on preference and intention were examined. Type of human intervention and level of biodiversity were treated as within-subject variables, whereas forest experience was a between-subject variable. We conducted the study in the spring of 2011 using an experimental design in a controlled setting at university campuses.

The first topic explored in this study concerned the effects of different types of human intervention on preference and intention. Previously, this issue has generally been examined in either forest management settings or in recreational settings. However, by including natural-looking scenes without obvious signs of human intervention, scenes with traces of recreation (e.g., paths), and scenes with traces of forest management (e.g., clear cuts), we could compare the effects of different types of human interventions. Since natural scenes without discriminable human intervention seem to hold qualities such as wilderness, according to the public $[29,48]$, it is possible to regard these scenes as natural-looking even though they have, at some point in time, been managed by humans. Preference was assessed to understand how these types of human interventions were evaluated, without considering a specific activity. Based on the reasoning that the impact of human interventions on preference can be positive or negative depending on visual appeal and the rationale behind the intervention (e.g., utilitarian or care) [28,29,32], the highest preference ratings can be expected for forest scenes with traces of recreation, followed by the natural-looking scenes, whilst the scenes with significantly visually evident traces of forest management should be least preferred. Since preference for the different categories depends on the forest scenes included in the study however, preference was in this study mainly considered a base line when analyzing intentions to engage in the different recreation activities.

Compatibility between an individual's goals and a setting is likely to result in a higher preference for being in that setting [49,50]. Hence, intention to engage in a certain activity in a specific setting should be determined by both the individual's own motivation to engage in that activity and the extent to which the setting supports that motivation. Regarding how supportive the setting is for different activities, we expected that settings with paths or roads would be more preferred for activities like walking, going on outings and especially exercising [2], whereas more natural-looking settings would be more suitable for activities like picking berries or mushrooms and studying plants and animals. Settings with traces of forest management tend to be negatively evaluated [14], and although other aspects may attract visitors to these settings (e.g., certain mushrooms grow on clear cuts), we expected the intention to engage in the examined activities in these settings to be weaker. Overall, we suggest that human intervention has different impacts depending on what people intend to do in the forest.

Since there may be a potential conflict between biodiversity and visual esthetics [37], the second issue addressed in this study concerns how the level of biodiversity influences preference and intention to engage in forest activities. Settings with low and high levels of biodiversity (rated by an expert) were compared. Although studies of forests have shown higher preference ratings for scenes with a low level of biodiversity [39], studies of other natural settings, such as rivers, have demonstrated the opposite results [41]. Furthermore, studies of how different levels of biodiversity 
influence intention to engage in specific recreation activities are lacking. Hence, no specific hypotheses were made beforehand.

The third topic examined in this study concerns the distinction between experts and non-experts, since this individual difference has often been found to be important in preference research. In this study, two groups with rather different forest experience were included: forestry and social science students. Even though the use of a student sample may limit conclusions, reviews indicate that students and the general public tend to have similar landscape preferences [44]. In addition, this student sample is interesting since many of the students (the forestry students in forest management and some of the social science students in land use planning) can be expected to work with planning issues after completing their studies. Based on previous studies [22,28], we expected the forestry students to prefer forest scenes with traces of forest management more compared to the social science students, and did not expect any great differences regarding preference for the other scenes. Stronger ecological values may result in higher preference for high biodiversity settings [38]. However, since we had no expectations regarding group differences in ecological values, no hypothesis was set up beforehand regarding how preference for settings with different levels of biodiversity would differ between the groups. Given that the forestry students are likely to display a stronger interest in the forest in general, however, we expected the forestry students to express stronger intentions to engage in the forest activities.

\section{Method}

\subsection{Participants}

A sample of 106 students participated in this study. The 75 social science students included 45 students recruited from the spatial planning program at Umeå University and 30 students from a course in macroeconomics at the Royal Institute of Technology (KTH) in Stockholm (these students could later select courses in spatial planning). The 31 forestry students were recruited from the Swedish University of Agriculture Sciences in Umeå. Participation was voluntary, and the study complied with ethical guidelines. All participants were given 99 Swedish kronor (approximate 16 US dollars).

An overview of the participants is given in Table 1. The gender distribution was even, and participants were between 19 and 34 years of age. Comparisons between the social science and forestry students demonstrate that the two samples did not differ in gender, age, or distance to the closest forest. However, the forestry students had grown up in rural areas to a greater extent and also visited forests for different activities more frequently compared to the social science students. In addition, the forestry students displayed stronger production values compared to the social science students, though the two groups did not differ in the endorsement of ecological and recreation values (for a description of the variables see 3.3. Measures of Subjects' Attributes). Hence, the two student groups were equivalent in many respects although, as expected, they had different forest experiences. 
Table 1. Background characteristics.

\begin{tabular}{|c|c|c|}
\hline & $\begin{array}{l}\text { Social science students } \\
\qquad(n=75)\end{array}$ & $\begin{array}{c}\text { Forestry students } \\
(n=31)\end{array}$ \\
\hline Women & $48 \%$ & $52 \%$ \\
\hline Mean age & 24 years $(3.1)$ & 22 years $(2.4)$ \\
\hline \multicolumn{3}{|l|}{ Childhood place of residence $* * *$} \\
\hline 200 or fewer residents & 10 & 42 \\
\hline $201-10,000$ residents & 30 & 45 \\
\hline $10,001-100,000$ residents & 38 & 13 \\
\hline 100,001 or more residents & 22 & 0 \\
\hline Distance to closest forest & $1.3 \mathrm{~km}(1.8)$ & $0.8 \mathrm{~km}(0.8)$ \\
\hline \multicolumn{3}{|c|}{ Frequency of forest recreation activities ${ }^{a}$} \\
\hline Walking & $3.04(0.83)$ & $3.71(0.69) * * *$ \\
\hline Going on outings & $2.19(0.51)$ & $2.52(0.77) *$ \\
\hline Picking berries or mushrooms & $2.08(0.59)$ & $2.68(0.87) * * *$ \\
\hline Exercising & $3.21(0.98)$ & $3.80(0.71) * *$ \\
\hline Studying plants and animals & $1.72(0.48)$ & $2.26(0.77) * * *$ \\
\hline Production values ${ }^{\mathrm{b}}$ & $3.93(1.21)$ & $5.29(0.94) * * *$ \\
\hline Recreation values ${ }^{b}$ & $4.66(1.31)$ & $4.10(1.56)$ \\
\hline Ecological values ${ }^{\mathrm{b}}$ & $6.05(1.13)$ & $6.29(0.74)$ \\
\hline
\end{tabular}

\subsection{Environmental Stimuli}

Photos of in-stand forest scenes were used as stimulus material. In total, 22 photos were included in the analyses. Eight photos showed natural-looking settings, eight included traces of recreational human intervention (i.e., paths, boardwalks or small roads), and six contained traces of forest management (i.e., clear cuts, re-growth on a clear cut or traces of forest machines). Half of the natural-looking scenes and half of the scenes with traces of recreation were coniferous forest with Scots Pine and Norway Spruce, and the other half were mixed forests (coniferous and deciduous). Both these forest types were included since they are common in Sweden. An overview of the forest scenes analyzed in this study is provided in Table 2.

Table 2. Overview of the forest scenes analyzed in this study.

\begin{tabular}{|c|c|c|c|c|}
\hline \multirow{2}{*}{$\begin{array}{c}\text { Type of human } \\
\text { intervention }\end{array}$} & \multirow{2}{*}{$\begin{array}{c}\text { Level of } \\
\text { biodiversity }\end{array}$} & \multicolumn{2}{|c|}{ Type of forest } & \\
\hline & & Coniferous & Mixed & \\
\hline \multirow{2}{*}{ Natural-looking } & Low & 2 & 2 & \\
\hline & High & 2 & 2 & \\
\hline \multirow{2}{*}{ Recreation } & Low & 2 & 2 & \\
\hline & High & 2 & 2 & \\
\hline Forest management & - & - & - & 6 \\
\hline
\end{tabular}


The photos were selected by the authors from a larger pool of photos. Photos representing the category of interest as well as possible were used, including a variety of different scenes within each category. None of the scenes included people or animals, and since water has been found to increase the attractiveness of natural environments [51], streams and lakes were excluded. Whereas some of the scenes displayed the forest in sunny conditions, others presented forests in cloudy weather. Notably, though, the different weather conditions were distributed approximately equally in the different categories. To categorize the forest scenes into low and high biodiversity, a professor in ecology performed an expert rating by evaluating the extent to which the scenes were perceived to provide conditions for viable populations of native plants and animal species (including threatened ones) following the environmental objectives set by the Swedish government [34]. Key aspects of the preservation of red-listed species are dead trees, deciduous trees and old trees [52]. The expert rating "very poorly" or "rather poorly" was perceived to represent a low level of biodiversity and the rating "rather well" or "very well" a high level of biodiversity. Since the scenes with traces of forest management mainly represented a low level of biodiversity according to this expert rating protocol, only the remaining 16 scenes were included in the analyses of biodiversity. The respondents were not given any information concerning what category the photos represented (i.e., type of human intervention or level of biodiversity). Examples of the study forest scenes are displayed in Figure 1.

Figure 1. Examples of forest scenes included in the study: (a) natural-looking, low biodiversity (coniferous); (b) recreation, low biodiversity (coniferous); (c) natural-looking, high biodiversity (mixed); (d) recreation, high biodiversity (mixed); (e) forest management: clear cut; (f) forest management: traces of forest machines.

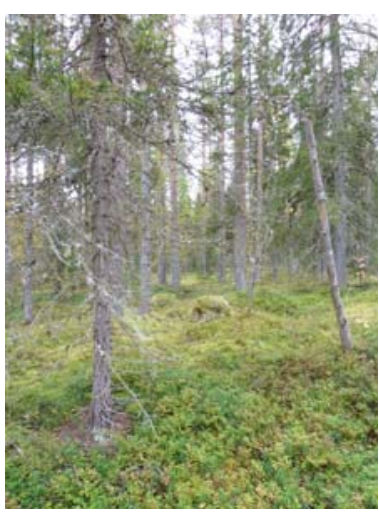

(a)

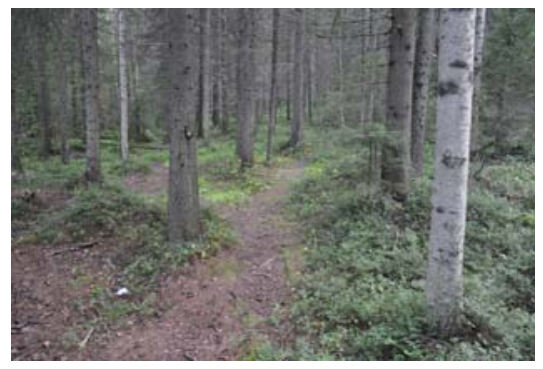

(d)

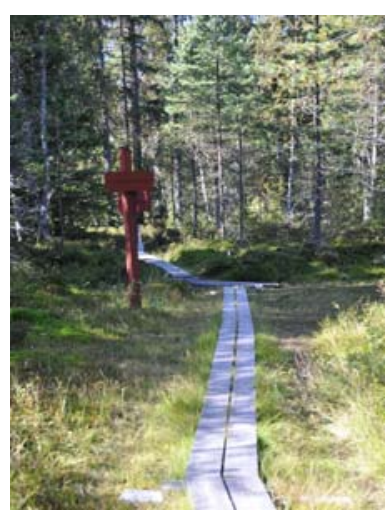

(b)

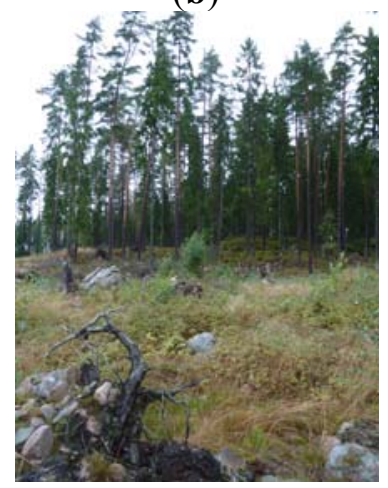

(e)

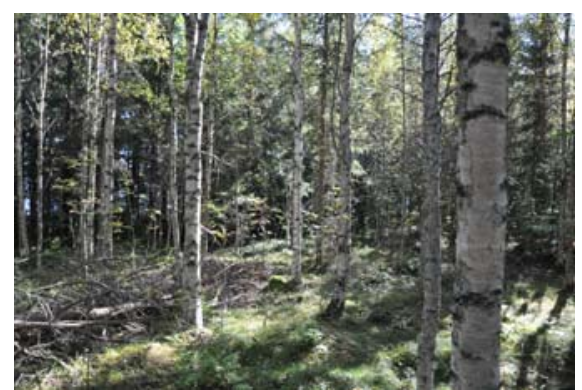

(c)

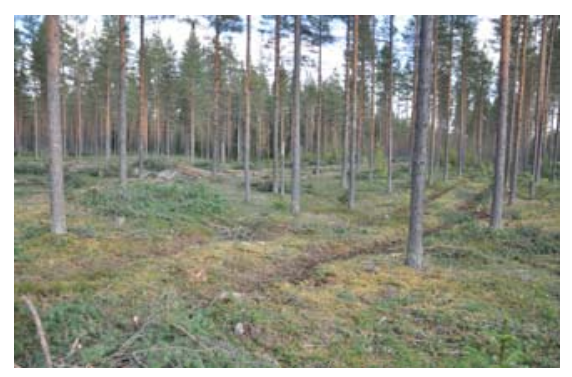

(f) 


\subsection{Measures of Subjects' Attributes}

Background variables, forest values and attitudes, as well as evaluations of each forest scene were assessed in the present study. Only the measures relevant to the research questions examined in this study are described below. Background questions included, for example, gender, age, size of the town where the respondent grew up, how often they carried out various forest activities, and distance from residence to closest forest. In addition, three types of forest values were assessed. The respondents stated the importance they attached to production values (i.e., increased timber production), recreation values (i.e., increased number of areas for recreation in the forest) and ecological values (i.e., preservation of plants and animals) on a seven-point scale ranging from not at all important to very important.

Preference and behavioral intentions were analyzed in relation to each forest scene. First, the five different behavioral intentions were measured using the following question: "Would you like to spend time in a forest setting like this one in order to: (1) walk, (2) go on outings (e.g., picnic), (3) pick berries or mushrooms, (4) exercise (e.g., cycle, run, ride), (5) study plants and animals (e.g., bird watching)?". The answers were provided on a four-point scale (absolutely not, probably not, yes maybe, yes definitely). Subsequently, the question "How much do you like this forest scene?" was used to assess visual preference and the response was given on a seven-point scale $(1=$ don't like it at all, $7=$ like it very much). The different response formats were used to reduce the risk of increasing the covariance between preference and intention based on similarities between scales rather than content [53].

\subsection{Procedure}

During three separate sessions (one student group in each), the study was carried out in lecture rooms on campus in Umeå and Stockholm, respectively. After the participants were provided with information about the study, they began by answering questions concerning their background and forest values. Subsequently, the forest scenes were evaluated. The scenes were shown in random order on a large screen using a projector. Each scene was first shown by itself for $8 \mathrm{~s}$ and then simultaneously with the questions ( $8 \mathrm{~s}$ for each question). The respondents evaluated a total of 25 scenes, although the first scene was used to introduce the students to the experiment and was therefore not included in the analyses, and two of the forest management scenes containing signs of brushwood and dead wood on the ground were excluded from the analyses since in retrospect it was not obvious that this was a result of recent forest management activities. After half of the forest scenes had been displayed, the participants were given a break of about five minutes. In total, one session took between 50 and 60 min to complete.

\section{Results}

Initially, indexes of preference and intentions were created by calculating the participants' mean ratings for each category. Subsequently, the internal reliability was assessed and results demonstrated reasonably high reliability, ranging from 0.64 to 0.94 (only three categories had alpha values below 
0.70) (see Tables 3 and 4). Since only marginal increases in alpha values could be achieved by excluding forest scenes, the 22 scenes were retained in the analyses.

\subsection{Type of Human Intervention}

Repeated measures ANOVAs were used to analyze the importance of type of human intervention for preference and intention with scene as within-subject factor and group as between-subject factor. Bonferroni corrections were used for the pairwise comparisons and in cases when the test of sphericity was significant, the Huynh and Feldt correction was used. Overall, results demonstrate that the distinction between different types of human intervention has an impact on preference and intention, as indicated by the relatively high explained variance ranging from $24 \%$ to $68 \%$ (see Table 3 ). Moreover, results reveal that the forestry students displayed stronger intentions to engage in recreation activities in the different forest settings compared to the social science students.

In relation to preference, forest scene type and the interaction between forest scene type and group were significant (Table 3, Panel a in Figure 2). The social science students liked the recreational scenes most, followed by the natural-looking scenes, and the least preferred were those with traces of forest management. In contrast, the forestry students preferred scenes with recreation and the natural-looking scenes equally and the forest management scenes were less appreciated. Inspection of the simple effects reveals that the largest group difference was found for scenes with traces of forest management, although the groups did not differ on a statistical significance level of $p<0.05$.

Regarding intentions to walk, go on outings and pick berries or mushrooms, significant main effects were found for forest scene type and group (Table 3). More specifically, the intentions to walk and to go on outings were strongest in forests with traces of recreation, followed by natural-looking forests. The weakest intentions to walk and to go on outings were found in settings with traces of forest management. In contrast, for picking berries or mushrooms, natural-looking settings were preferred more than those with traces of either recreation or forest management. In relation to all three activities, the forestry students displayed stronger intentions than the social science students.

Significant main effects were also demonstrated for forest scene type and group in relation to intention to exercise and study plants and animals. In addition, significant interactions were revealed, indicating that a closer inspection of the simple interaction effects is warranted (Table 3). Both student groups displayed a stronger intention to exercise in recreational settings than in the other settings. Moreover, compared to the social science students, the forestry students displayed a stronger intention to exercise in recreational settings and in natural-looking settings, although no group difference was found for settings with traces of forest management (Panel b in Figure 2). The intention to study plants and animals was equally strong for the different settings among the social science students, whereas the forestry students displayed a stronger intention to study plants and animals in natural-looking settings compared to settings with traces of forest management (Panel c in Figure 2). 
Table 3. Internal reliability $(\alpha)$, means, standard deviations, and results from the repeated measures ANOVAs in relation to preference and intention to engage in activities in settings with different types of human intervention (i.e., natural-looking, settings with traces of recreation, and settings with traces of forest management) among the social science and forestry students.

\begin{tabular}{|c|c|c|c|c|c|c|}
\hline & \multicolumn{3}{|c|}{ Internal reliability $(\alpha)$, means and standard deviations } & \multicolumn{3}{|c|}{ Repeated measures ANOVAs } \\
\hline & Natural-looking $(n=8)$ & Recreation $(n=8)$ & $\begin{array}{c}\text { Forest management } \\
\qquad(n=6)\end{array}$ & $\begin{array}{c}\text { Main effect: } \\
\text { Scene } \\
\end{array}$ & $\begin{array}{c}\text { Main effect: } \\
\text { Group }\end{array}$ & $\begin{array}{c}\text { Interaction: Scene } \\
\text { and Group }\end{array}$ \\
\hline \multirow{3}{*}{$\begin{array}{l}\text { Preference } \\
\text { Social science students } \\
\text { Forestry students }\end{array}$} & $\alpha=0.77$ & $\alpha=0.71$ & $\alpha=0.74$ & & \multirow{4}{*}{ n.s. } & \multirow{4}{*}{$\begin{array}{c}F=5.302 \\
p=0.01 \\
\text { partial } \eta^{2}=0.05\end{array}$} \\
\hline & $4.90(0.85)$ & $5.47(0.71)$ & $3.92(0.94)$ & $F=67.55$ & & \\
\hline & $5.11(0.66)$ & $5.27(0.69)$ & $4.41(0.87)$ & $p=0.001$ & & \\
\hline Total & $4.96(0.80)$ & $5.41(0.71)$ & $4.07(0.95)$ & partial $\eta^{2}=0.39$ & & \\
\hline \multirow{4}{*}{$\begin{array}{l}\text { Walk } \\
\text { Social science students } \\
\text { Forestry students }\end{array}$} & $\alpha=0.83$ & $\alpha=0.75$ & $\alpha=0.75$ & \multirow{4}{*}{$\begin{array}{c}F=189.41 \\
p=0.001 \\
\text { partial } \eta^{2}=0.65\end{array}$} & \multirow{4}{*}{$\begin{array}{c}\qquad \begin{array}{c}F=5.81 \\
p=0.02\end{array} \\
\text { partial } \eta^{2}=0.05\end{array}$} & \multirow{4}{*}{ n.s. } \\
\hline & $2.95(0.56)$ & $3.67(0.35)$ & $2.51(0.55)$ & & & \\
\hline & $3.25(0.44)$ & $3.77(0.26)$ & $2.68(0.63)$ & & & \\
\hline & $3.04(0.54)$ & $3.70(0.33)$ & $2.56(0.58)$ & & & \\
\hline \multirow{4}{*}{$\begin{array}{l}\text { Outings } \\
\text { Social science students } \\
\text { Forestry students }\end{array}$} & $\alpha=0.75$ & $\alpha=0.75$ & $\alpha=0.64$ & \multirow{4}{*}{$\begin{array}{c}\qquad \begin{array}{l}F=78.77 \\
p=0.001\end{array} \\
\text { partial } \eta^{2}=0.43\end{array}$} & \multirow{4}{*}{$\begin{array}{c}\quad F=5.97 \\
p=0.02 \\
\text { partial } \eta^{2}=0.05\end{array}$} & \multirow{4}{*}{ n.s. } \\
\hline & $2.51(0.52)$ & $2.84(0.53)$ & $2.10(0.48)$ & & & \\
\hline & $2.85(0.47)$ & $2.98(0.53)$ & $2.20(0.46)$ & & & \\
\hline & $2.61(0.53)$ & $2.88(0.54)$ & $2.13(0.47)$ & & & \\
\hline \multirow{3}{*}{$\begin{array}{l}\text { Pick berries or mushrooms } \\
\text { Social science students } \\
\text { Forestry students }\end{array}$} & $\alpha=0.87$ & $\alpha=0.82$ & $\alpha=0.82$ & \multirow{4}{*}{$\begin{array}{c}F=71.52 \\
p=0.001 \\
\text { partial } \eta^{2}=.41\end{array}$} & \multirow{4}{*}{$\begin{array}{c}F=7.53 \\
p=0.01 \\
\text { partial } \eta^{2}=0.07\end{array}$} & \multirow{4}{*}{ n.s. } \\
\hline & $3.00(0.61)$ & $2.58(0.57)$ & $2.46(0.63)$ & & & \\
\hline & $3.36(0.31)$ & $2.76(0.45)$ & $2.78(0.57)$ & & & \\
\hline Total & $3.10(0.56)$ & $2.63(0.54)$ & $2.56(0.63)$ & & & \\
\hline \multirow{4}{*}{$\begin{array}{l}\text { Exercise } \\
\text { Social science students } \\
\text { Forestry students }\end{array}$} & $\alpha=0.91$ & $\alpha=0.84$ & $\alpha=0.84$ & \multirow{4}{*}{$\begin{array}{c}F=220.11 \\
p=0.001 \\
\text { partial } \eta^{2}=0.68\end{array}$} & \multirow{4}{*}{$\begin{array}{c}F=12.51 \\
p=0.001 \\
\text { partial } \eta^{2}=0.11\end{array}$} & \multirow{4}{*}{$\begin{array}{c}\quad F=3.31 \\
p=0.05 \\
\text { partial } \eta^{2}=0.03\end{array}$} \\
\hline & $2.13(0.71)$ & $3.19(0.58)$ & $2.04(0.65)$ & & & \\
\hline & $2.70(0.58)$ & $3.51(0.30)$ & $2.34(0.61)$ & & & \\
\hline & $2.29(0.72)$ & $3.28(0.54)$ & $2.12(0.65)$ & & & \\
\hline \multirow{4}{*}{$\begin{array}{l}\text { Study plants and animals } \\
\text { Social science students } \\
\text { Forestry students }\end{array}$} & $\alpha=0.94$ & $\alpha=0.92$ & $\alpha=0.89$ & \multirow{4}{*}{$\begin{array}{c}F=32.58 \\
p=0.001 \\
\text { partial } \eta^{2}=0.24\end{array}$} & \multirow{4}{*}{$\begin{array}{c}F=25.33 \\
p=0.001 \\
\text { partial } \eta^{2}=0.20\end{array}$} & \multirow{4}{*}{$\begin{array}{c}F=6.35 \\
p=0.01 \\
\text { partial } \eta^{2}=0.06\end{array}$} \\
\hline & $2.35(0.79)$ & $2.22(0.69)$ & $2.12(0.72)$ & & & \\
\hline & $3.11(0.44)$ & $3.00(0.48)$ & $2.60(0.55)$ & & & \\
\hline & $2.57(0.79)$ & $2.45(0.72)$ & $2.26(0.71)$ & & & \\
\hline
\end{tabular}

Scales. Preference: $1-7(1=$ don't like it at all, $7=$ like it very much). Behavioral intentions: $1-4(1=$ absolutely not, $2=$ probably not, $3=$ yes maybe, $4=$ yes definitely $)$. n.s. $=$ not significant. 
Figure 2. Two-way interactions between type of human intervention and group: (a) Preference as a function of human intervention and group, (b) intention to exercise as a function of human intervention and group, (c) intention to study plants and animals as a function of human intervention and group.

(a)

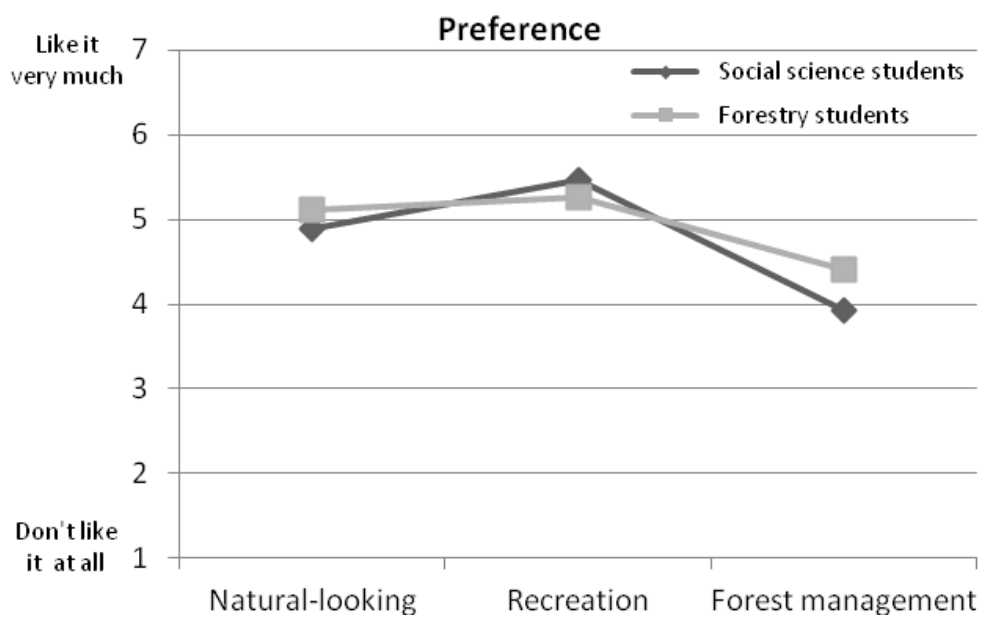

(b)
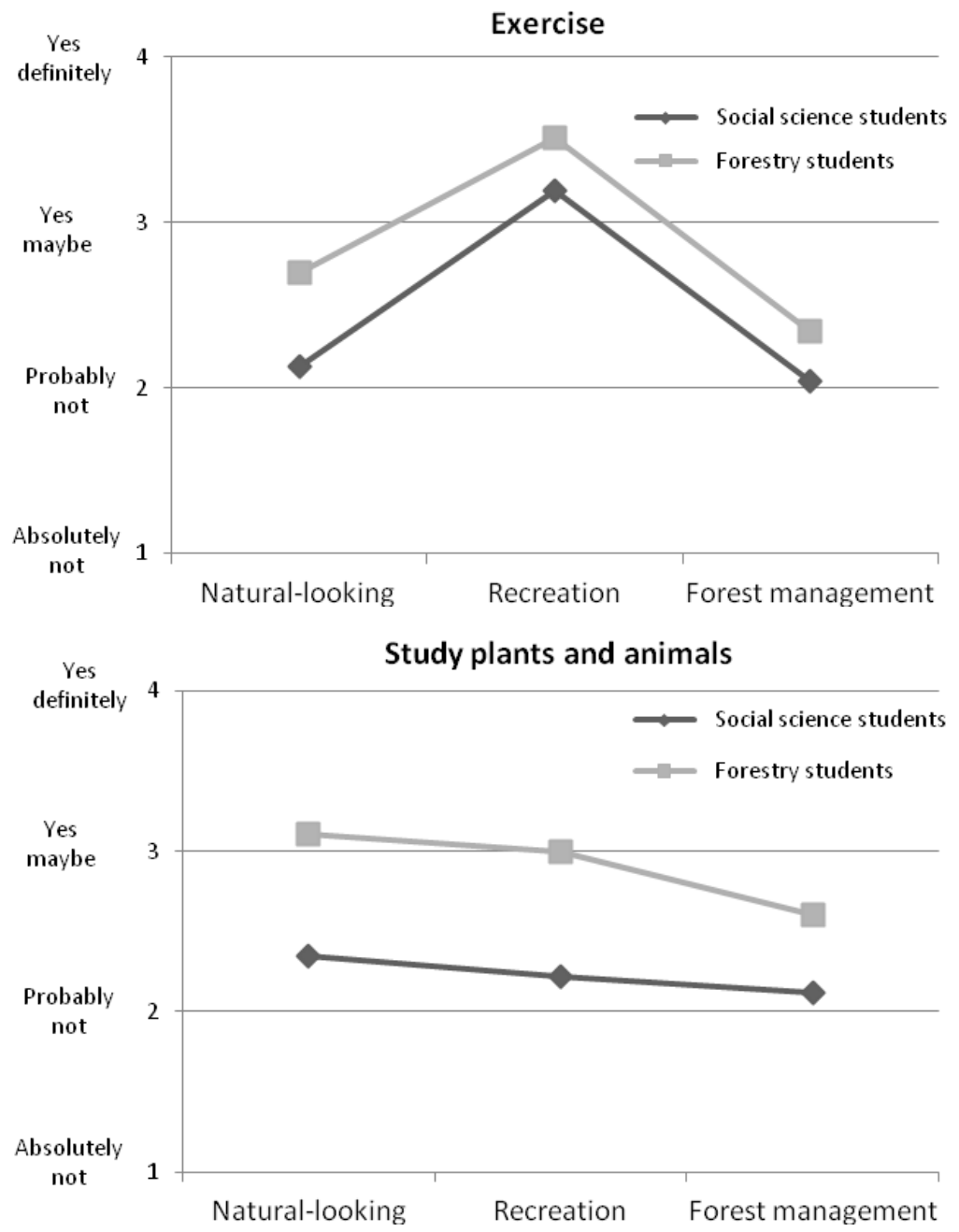


\subsection{Level of Biodiversity}

The effect of biodiversity levels on preference and intention was analyzed using repeated measures ANOVAs (scene as within-subject factor and group as between-subject factor, excluding scenes with traces of forest management). Bonferroni corrections were used for the pairwise comparisons, and in cases when the test of sphericity was significant, we employed the Huynh and Feldt correction (see Table 4).

Results demonstrate that scene type was only significant in relation to preference, intention to study plants and animals, and intention to exercise. More specifically, respondents displayed higher preference for scenes with high biodiversity and stronger intention to study plants and animals in these settings, although the intention to exercise was stronger in settings with low levels of biodiversity. Notably, the level of explained variance was relatively low, ranging from $4 \%$ to $19 \%$. The forestry students and the social science students did not differ in preference for scenes with different levels of biodiversity, although the forestry students displayed stronger intentions to engage in all the examined activities than the social science students. None of the interactions between level of biodiversity and group were significant.

\subsection{Summary of Findings}

In line with expectations, the social science students displayed a greater preference for recreational scenes compared to natural-looking scenes. However, the forestry students displayed an almost equally strong preference for natural scenes as for scenes with traces of recreation. Both groups had the lowest preference ratings of the forest management settings. The study participants furthermore preferred to walk, go on outings, and exercise in recreational settings whilst natural-looking settings were favored for picking berries or mushrooms. Moreover, also in line with our expectations, the forestry students had a stronger intention to study plants and animals in natural-looking settings than in settings with traces of forest management. In contrast, the social science students displayed a weak intention to study plants and animals and did not differentiate between the forest settings regarding this activity. Results furthermore demonstrated that respondents preferred scenes with high biodiversity and displayed a stronger intention to study plants or animals in high biodiversity settings, though the intention to exercise was stronger in settings with a low level of biodiversity. 
Table 4. Internal reliability $(\alpha)$, means, standard deviations, and results from the repeated measures ANOVAs in relation to preference and intention to engage in activities in settings with low and high levels of biodiversity among the social science and forestry students.

\begin{tabular}{|c|c|c|c|c|c|c|}
\hline & & \multicolumn{2}{|c|}{ Internal reliability $(\alpha)$, means and standard deviations } & \multicolumn{3}{|c|}{ Repeated measures ANOVAs } \\
\hline & & $\begin{array}{c}\text { Low biodiversity } \\
(n=8)\end{array}$ & $\begin{array}{l}\text { High biodiversity } \\
\quad(n=8)\end{array}$ & $\begin{array}{l}\text { Main effect: } \\
\text { Scene }\end{array}$ & $\begin{array}{c}\text { Main effect: } \\
\text { Group }\end{array}$ & $\begin{array}{c}\text { Interaction: Scene } \\
\text { and Group }\end{array}$ \\
\hline Preference & & $\alpha=0.64$ & $\alpha=0.66$ & & \multirow{4}{*}{ n.s. } & \multirow{4}{*}{ n.s. } \\
\hline Social science students & & $5.09(0.71)$ & $5.28(0.71)$ & $F=11.41$ & & \\
\hline \multirow[t]{2}{*}{ Forestry students } & & $5.07(0.57)$ & $5.31(0.65)$ & $p=0.001$ & & \\
\hline & Total & $5.09(0.67)$ & $5.29(0.69)$ & partial $\eta^{2}=0.10$ & & \\
\hline Walk & & $\alpha=0.71$ & $\alpha=0.73$ & \multirow{4}{*}{ n.s. } & & \multirow{4}{*}{ n.s. } \\
\hline Social science students & & $3.29(0.38)$ & $3.32(0.43)$ & & $F=7.26$ & \\
\hline \multirow{2}{*}{ Forestry students } & & $3.48(0.34)$ & $3.54(0.34)$ & & $p=0.01$ & \\
\hline & Total & $3.35(0.38)$ & $3.39(0.42)$ & & partial $\eta^{2}=0.07$ & \\
\hline Outings & & $\alpha=0.72$ & $\alpha=0.69$ & \multirow{4}{*}{ n.s. } & & \multirow{4}{*}{ n.s. } \\
\hline Social science students & & $2.61(0.49)$ & $2.73(0.50)$ & & $F=6.40$ & \\
\hline \multirow[t]{2}{*}{ Forestry students } & & $2.91(0.44)$ & $2.92(0.50)$ & & $p=0.01$ & \\
\hline & Total & $2.70(0.49)$ & $2.79(0.51)$ & & partial $\eta^{2}=0.06$ & \\
\hline \multicolumn{2}{|c|}{ Pick berries or mushrooms } & $\alpha=0.81$ & $\alpha=0.82$ & \multirow{4}{*}{ n.s. } & & \multirow{4}{*}{ n.s. } \\
\hline \multicolumn{2}{|l|}{ Social science students } & $2.78(0.53)$ & $2.79(0.60)$ & & $F=6.66$ & \\
\hline \multirow[t]{2}{*}{ Forestry students } & & $3.06(0.35)$ & $3.05(0.34)$ & & $p=0.01$ & \\
\hline & Total & $2.86(0.50)$ & $2.87(0.55)$ & & partial $\eta^{2}=0.06$ & \\
\hline \multirow{4}{*}{$\begin{array}{l}\text { Exercise } \\
\text { Social science students } \\
\text { Forestry students }\end{array}$} & & $\alpha=0.81$ & $\alpha=0.85$ & \multirow{4}{*}{$\begin{array}{c}F=4.28 \\
p=0.04 \\
\text { partial } \eta^{2}=0.04\end{array}$} & \multirow{4}{*}{$\begin{array}{c}F=16.13 \\
p=0.001 \\
\text { partial } \eta^{2}=0.13\end{array}$} & \multirow{4}{*}{ n.s. } \\
\hline & & $2.71(0.54)$ & $2.61(0.61)$ & & & \\
\hline & & $3.12(0.34)$ & $3.08(0.49)$ & & & \\
\hline & Total & $2.83(0.53)$ & $2.75(0.62)$ & & & \\
\hline \multirow{4}{*}{$\begin{array}{l}\text { Study plants and animals } \\
\text { Social science students } \\
\text { Forestry students }\end{array}$} & & $\alpha=0.93$ & $\alpha=0.93$ & & & \multirow{4}{*}{ n.s. } \\
\hline & & $2.23(0.69)$ & $2.34(0.78)$ & $F=23.84$ & $F=30.98$ & \\
\hline & & $2.95(0.45)$ & $3.15(0.44)$ & $p=0.001$ & $p=0.001$ & \\
\hline & Total & $2.44(0.71)$ & $2.58(0.79)$ & partial $\eta^{2}=0.19$ & partial $\eta^{2}=0.23$ & \\
\hline
\end{tabular}

Scales. Preference: $1-7(1=$ don't like it at all, $7=$ like it very much). Behavioral intentions: $1-4(1=$ absolutely not, $2=$ probably not, $3=$ yes maybe, $4=$ yes definitely $)$. n.s. $=$ not significant. 


\section{Discussion}

\subsection{Activity Preferences in Forest Settings}

By drawing on the landscape preference approach, the links between setting characteristics and forest recreation activities were explored in this scene preference study. Results confirmed that different forest settings are preferred for different recreation activities, thus extending previous research $[13,14]$ to identify additional activity preferences associated with different types of settings. In line with previous studies [49,50], the importance of both the motivation to engage in a certain activity and the extent to which the setting supports this motivation were revealed in the present study. For example, it was evident that the respondents' intention to walk was strong overall, although setting characteristics were also important. For example, type of human intervention was essential for explaining preference ratings (almost 40\%) as well as for intentions to engage in several of the activities, particularly walking and exercising (around 65\%) but also going on outings and picking berries or mushrooms (around 40\%). Given that the recreational settings all included a path of some kind, it is not surprising that the classification was particularly influential for activities such as walking and exercising. Paths are likely to facilitate these activities and thus promote goal achievement [54].

Overall, the classification into different types of human intervention seems to be useful not only to understand preference [30], but also to clarify how settings are evaluated in relation to specific recreation activities. Although preference, or scenic beauty, is likely to be important, at least for some activities [3], the present study demonstrated that what people value most depends to some extent on what they intend to do in the forest. To develop the understanding of how preference and different recreation activities are related, it may be fruitful to draw on attitude-behavior research [16]. High preference for a forest scene is comparable to having a positive attitude towards that scene, and may lead to a stronger intention to visit it. However, as suggested by the theory of planned behavior (a well-known attitude-behavior theory), attitude is not the sole predictor of intention; subjective norm and perceived behavioral control are also important [55].

\subsection{Forest Recreation and Setting Experience}

Although results reveal a general pattern by which certain activities are more compatible with certain settings [50], differences between the student groups indicate that forest experience modifies this relation. Although group differences in preference were marginal, the pattern of results was in line with previous studies in which foresters have been found to prefer scenes with obvious signs of forest management more than others [28]. Previous studies suggest that foresters interpret forest management scenes differently, and that the interpretation of such scenes plays a significant role in forming visual preference [56]. Hence, the evaluation of forest management or recreation activities themselves may be important for how people interpret settings bearing traces of these activities. Since the forestry students in this study emphasized forest production more than recreation, they may be more likely to look at forest management in a less negative light and forest recreation in a less positive light compared to others. Indeed, the negative impact of traces of forest management and the positive impact of traces of recreation, compared to natural-looking scenes, were smaller among the forestry students than among the social science students. It thus seems as if there is more to preference than what is presented 
visually, though more research needs to examine the extent to which visual cues versus underlying reasons for the intervention are incorporated into preference ratings.

In contrast to preference, group differences in intentions were actually least evident in forest management settings and slightly larger in natural-looking settings, being most apparent in relation to exercising but noticeable also in relation to walking and going on outings. These results suggest that compared to the social science students, the forestry students may have interpreted the natural-looking settings as also suitable for these activities to a larger extent. Future studies need to continue to examine sub-groups with different values, attitudes, and forest experience (e.g., different recreational groups) to understand reasons for engaging in recreation activities in specific forest settings.

\subsection{Forest Recreation and Biodiversity}

The present study found no evidence of a conflict between biodiversity and visual esthetics as suggested by, for example Parsons [37]. Although studies have revealed a higher preference for certain low biodiversity forest scenes [39], the results from the present study are in line with several other studies in which preference has been found to be generally higher for high biodiversity settings [43]. One interpretation is that whereas certain aspects indicative of high biodiversity (e.g., dead wood) may be disliked, other aspects such as lush vegetation may be liked. Hence, when comparing a range of different forest scenes categorized into low versus high biodiversity, it is not certain that low biodiversity scenes will necessarily be preferred. As a result, the simple negative relation between level of biodiversity and preference may only be found when focusing on only one indicator of biodiversity. The results should also be interpreted considering the rather strong ecological values found in the respondent sample, which may have led to stronger preference for high biodiversity forests even if the respondents were not informed of the biodiversity levels [38]. Notably, though, the present study demonstrated that the intention to exercise was significantly stronger in settings with low levels of biodiversity than in those with high levels. Results thus indicate that individuals may be particularly sensitive to different indicators of biodiversity when engaging in certain activities. Overall, though, biodiversity seems to be of minor importance for determining people's visual preference as suggested by the rather low internal consistency of the preference measures. In addition, the classification into low versus high biodiversity only explained a small amount of variance in preference and intention (ranging from $0 \%$ to $19 \%$ ).

\subsection{Limitations}

When interpreting the results of this study, its limitations should be considered. For example, different forest settings in the stimulus material may have resulted in a different pattern of results. Notably, though, preference ratings were comparable to previous studies [28] and intentions differed depending on activity, suggesting that biases in the selection process (e.g., that more beautiful scenes had been included in one of the categories) could not explain the main results. Furthermore, even though the respondent sample was limited and only included students, the expected differences between the forestry and social science students were identified [12,28]. 


\section{Conclusions}

Forests are important for outdoor recreation and to be able to encourage forest recreation there is a need to understand what type of forests people would like to visit. The appearances of forests differ depending on whether environmental, production or social forest objectives are pursued in forest management. For example, attempting to increase environmental values may involve leaving dead wood in the forest to increase biodiversity. In contrast, emphasizing production values may lead to more tree felling with large clear cuts as a result, and endorsing social objectives may result in forests bearing more evident traces of humans, such as paths. A conflict between production and social objectives can occur, since people do not want to visit forest settings with obvious traces of production activities. However, the present study demonstrated that both more natural settings without signs of human intervention as well as recreational settings are needed to facilitate forest recreation, since different activities are suitable for different settings. In general, the present study did not find evidence of a conflict between forest recreation and biodiversity (i.e., social and environmental objectives), although certain activities like exercising may be less suitable in forests with a high level of biodiversity.

Moreover, results point to a potential conflict between planning professionals. Since the forestry students are likely to work in the field of forest management, and at least some of the social science students as land use planners in municipalities, for example, differences between these groups may be indicative of discrepancies concerning what different planning professionals believe the forest should look like in the future. Finally, since it is likely that the general public is more similar to the social science students than the forestry students, forest planning professionals may endorse slightly different social values than the public.

\section{Acknowledgments}

This research was funded by Future Forests, a multidisciplinary research program, and its sponsors: the Strategic Foundation for Environmental Research (Mistra), the Swedish University of Agricultural Sciences (SLU), Umeå University, the Forestry Research Institute of Sweden (Skogforsk), and the forestry industry in Sweden. We sincerely thank Professor Lena Gustafsson, Department of Ecology, Swedish University of Agricultural Sciences (SLU), Uppsala, Sweden, for evaluating the level of biodiversity of the forest scenes and three anonymous reviewers for their comments on an earlier draft of this paper.

\section{Conflict of Interest}

The authors declare no conflict of interest.

\section{References}

1. Pouta, E.; Sievänen, T.; Neuvonen, M. Recreational wild berry picking in Finland-Reflection of a rural life style. Soc. Nat. Resour. 2006, 19, 285-304. 
2. Roovers, P.; Hermy, M.; Gulinck, H. Visitor profile, perceptions and expectations in forests from a gradient of increasing urbanization in central Belgium. Landsc. Urban Plan. 2002, 59, 129-145.

3. Ribe, R.G. Scenic beauty perceptions along the ROS. J. Environ. Manag. 1994, 42, 199-221.

4. Karjalainen, E.; Sarjala, T.; Raitio, H. Promoting human health through forests: Overview and major challenges. Environ. Health Prev. Med. 2010, 15, 1-8.

5. Degenhardt, B.; Frick, J.; Buchecker, M.; Gutscher, H. Influences of personal, social, and environmental factors on workday use frequency of the nearby outdoor recreation areas by working people. Leis. Sci. 2011, 33, 420-440.

6. Kangas, K.; Markkanen, P. Factors affecting participating in wild berry picking by rural and urban dwellers. Silva Fenn. 2001, 35, 487-495.

7. Jensen, F.S.; Koch, N.E. Twenty-five years of forest recreation research in Denmark and its influence on forest policy. Scand. J. For. Res. 2004, 19, 93-102.

8. Hunt, L.; Twynam, G.D.; Haider, W.; Robinson, D. Examining the desirability for recreating in logged settings. Soc. Nat. Resour. 2000, 13, 717-734.

9. Van Rieper, C.J.; Manning, R.E.; Monz, C.A.; Goonan, K.A. Tradeoffs among resource, social, and managerial conditions on mountain summits of the northern forest. Leis. Sci. 2011, 33, 228-249.

10. Brown, T.C.; Daniel, T.C. Predicting scenic beauty of timber stands. For. Sci. 1986, 32, 471-487.

11. Ribe, R.G. In-stand scenic beauty of variable retention harvests and mature forests in the U.S. Pacific Northwest: The effects of basal area, density, retention pattern and down wood. J. Environ. Manag. 2009, 91, 245-260.

12. Tönnes, S.; Karjalainen, E.; Löfström, I.; Neuvonen, M. Scenic impacts of retention trees in clear-cutting areas. Scand. J. For. Res. 2004, 19, 348-357.

13. Gan, J.; Kolison, S.H.; Miller, J.H. Public preferences for nontimber benefits of loblolly pine (Pinus taede) stands regenerated by different site preparation methods. South. J. Appl. For. 2000, 24, 145-149.

14. Shelby, B.; Thompson, J.R.; Brunson, M.; Johnson, R. A decade of recreation ratings for six silviculture treatments in Western Oregon. J. Environ. Manag. 2005, 75, 239-246.

15. Tahvanainen, L.; Tyrväinen, L.; Ihalainen, M.; Vuorela, N.; Kolehmainen, O. Forest management and public perceptions - Visual versus verbal information. Landsc. Urban Plan. 2001, 53, 53-70.

16. Singh, S.N.; Donavan, D.T.; Mishra, S.; Little, T.D. The latent structure of landscape perception: A mean and covariance structure modeling approach. J. Environ. Psychol. 2008, 28, 339-352.

17. The Right of Public Access, 2011. Swedish Environmental Protection Agency. Available online: http://www.naturvardsverket.se/en/In-English/Start/Enjoying-nature/The-right-of-public-access/ (accessed on 11 June 2012).

18. Vilka är ute i naturen? Delresultat från en nationell enkät om friluftsliv och naturturism i Sverige (Who Visits Nature? Results from a Nationwide Questionnaire Study of Outdoor Life and Nature Tourism in Sweden); Report No. 1; Fredman, P., Karlsson, S.-E., Romild, U., Sandell, K., Eds.; Forskningsprogrammet friluftsliv i förändring: Östersund, Sweden, 2008.

19. Kellomäki, S.; Savolainen, R. The scenic value of the forest landscape assessed in field and laboratory. Landsc. Plan. 1984, 11, 97-107. 
20. Zube, E.H.; Simcox, D.E.; Law, C.S. Perceptual landscape simulations: History and prospect. Landsc. J. 1987, 6, 62-80.

21. Manning, R.E.; Freimund, W.A. Use of visual research methods to measure standards of quality for parks and outdoor recreation. J. Leis. Res. 2004, 36, 557-579.

22. Gundersen, V.S.; Frivold, L.H. Public preferences for forest structures: A review of quantitative surveys from Finland, Norway, and Sweden. Urban For. Urban Green. 2008, 7, 241-258.

23. Ribe, R.G. The aesthetics of forestry: What has empirical preference research taught us? Environ. Manag. 1989, 13, 55-74.

24. Ryan, R.L. Social Science to Improve Fuels Management: A Synthesis of Research on Aesthetics and Fuels Management; General Technical Report NC-261; U.S. Department of Agriculture, Forest Service, North Central Research Station: St. Paul, MN, USA, 2005.

25. Herzog, T.R.; Kutzli, G.E. Preference and perceived danger in field/forest settings. Environ. Behav. 2002, 34, 819-835.

26. Herzog, T.R.; Herbert, E.J.; Kaplan, R.; Crooks, C.L. Cultural and developmental comparisons of landscape perceptions and preferences. Environ. Behav. 2000, 32, 323-346.

27. Hartig, T.; Evans, G.W. Psychological Foundations of Nature Experience. In Behavior and Environment: Psychological and Geographical Approaches; Gärling, T., Golledge, R.G., Eds.; Elsevier Science Publishers: Amsterdam, the Netherlands, 1993; pp. 427-457.

28. Kearney, A.R.; Bradley, G.A. The effects of viewer attributes on preference for forest scenes: Contributions of attitudes, knowledge, demographic factors, and stakeholder group membership. Environ. Behav. 2011, 43, 147-181.

29. Van den Berg, A.E.; Koole, S.L. New wilderness in the Netherlands: An investigation of visual preferences for nature development landscapes. Landsc. Urban Plan. 2006, 78, 362-372.

30. Real, E.; Arce, C.; Sabucedo, J.M. Classification of landscapes using quantitative and categorical data, and prediction of their scenic beauty in north-western Spain. J. Environ. Psychol. 2000, 20, 355-373.

31. Jensen, F.S. The effects of information on Danish forest visitors' acceptance of various management actions. Forestry 2000, 73, 165-172.

32. Sheppard, S.R.J. Beyond Visual Resource Management: Emerging Theories of an Ecological Aesthetic and Visible Stewardship. In Forests and Landscapes. Linking Ecology, Sustainability, and Aesthetics; IUFRO Research Series 6; Sheppard, S.R.J., Harshaw, H.W., Eds.; CABI Publishing: Wallingford, UK, 2001; pp. 149-172.

33. Secretariat of the Convention on Biological Diversity. Sustaining Life on Earth. How the Convention on Biological Diversity Promotes Nature and Human Well-Being; United Nations Environment Programme: Montreal, Canada, 2000.

34. Swedish Environmental Protection Agency. Sweden's Environmental Objectives in an Interdependent World - de Facto 2007; Swedish Environmental Protection Agency: Stockholm, Sweden, 2007.

35. Swedish Forest Agency. Quantitative Targets of Swedish Forest Policy; Swedish Forest Agency: Jönköping, Sweden, 2005.

36. Nassauer, J.I. Messy ecosystems, orderly frames. Landsc. J. 1995, 14, 161-170. 
37. Parsons, R. Conflict between ecological sustainability and environmental aesthetics: Conundrum, canärd or curiosity. Landsc. Urban Plan. 1995, 32, 227-244.

38. Gobster, P.H. An ecological aesthetic for forest landscape management. Landsc. J. 1999, 18, 54-64.

39. Gundersen, V.S.; Frivold, L.H. Naturally dead and downed wood in Norwegian boreal forests: Public preferences and the effect of information. Scand. J. For. Res. 2011, 26, 110-119.

40. Williams, K.J.H.; Cary, J. Landscape preferences, ecological quality, and biodiversity protection. Environ. Behav. 2002, 34, 257-274.

41. Junker, B.; Buchecker, M. Aesthetic preferences versus ecological objectives in river restorations. Landsc. Urban Plan. 2008, 85, 141-154.

42. Kurz, T.; Baudains, C. Biodiversity in the front yard: An investigation of landscape preference in a domestic urban context. Environ. Behav. 2012, 44, 166-196.

43. Lafortezza, R.; Corry, R.C.; Sanesi, G.; Brown, R.D. Visual preference and ecological assessments for designed alternative brownfield rehabilitations. J. Environ. Manag. 2008, 89, 257-269.

44. Stamps, A.E. Psychology and the Aesthetics of the Built Environment; Kluwer: Boston, MA, USA, 2000.

45. Ribe, R.G. Is scenic beauty a proxy for acceptable management? The influence of environmental attitudes on landscape perceptions. Environ. Behav. 2002, 34, 757-780.

46. Kearney, A.R.; Tilt, J.R.; Bradley, G.A. The effects of forest regeneration on preferences for forest treatments among foresters, environmentalists, and the general public. J. For. 2010, 108, 215-229.

47. Schwenk, G.; Möser, G. Intention and behavior: A Bayesian meta-analysis with focus on the Ajzen-Fishbein Model in the field of environmental behavior. Qual. Quant. 2009, 43, 743-755.

48. Kaplan, R.; Kaplan, S. The Experience of Nature: A Psychological Perspective; Cambridge University Press: New York, NY, USA, 1989.

49. Kaplan, S. Meditation, restoration, and the management of mental fatigue. Environ. Behav. 2001, 33, 480-506.

50. Herzog, T.R.; Hayes, L.J.; Applin, R.C.; Weatherly, A.M. Compatibility: An experimental demonstration. Environ. Behav. 2011, 43, 90-105.

51. White, M.; Smith, A.; Humphryes, K.; Pahl, S.; Snelling, D.; Depledge, M. Blue space: The importance of water for preference, affect, and restorativeness ratings of natural and built scenes. J. Environ. Psychol. 2010, 30, 482-493.

52. Berg, Å.; Ehnström, B.; Gustafsson, L.; Hallingbäck, T.; Jonsell, M.; Weslien, J. Threatened forest plants, animals and fungus species in Swedish forests-Distribution and habitat associations. Conserv. Biol. 1994, 8, 718-731.

53. Podsakoff, P.M.; MacKenzie, S.B.; Lee, J.-Y.; Podsakoff, N.P. Common method biases in behavioral research: A critical review of the literature and recommended remedies. J. Appl. Psychol. 2003, 88, 879-903.

54. Canter, D. The purposive evaluation of places. A facet approach. Environ. Behav. 1983, 15, 659-698.

55. Ajzen, I. The theory of planned behavior. Organ. Behav. Hum. Dec. 1991, 50, 179-211. 
56. Bradley, G.A.; Kearney, A.R. Public and professional responses to the visual effects of timber harvesting: Different ways of seeing. West. J. Appl. For. 2007, 22, $42-54$.

(C) 2012 by the authors; licensee MDPI, Basel, Switzerland. This article is an open access article distributed under the terms and conditions of the Creative Commons Attribution license (http://creativecommons.org/licenses/by/3.0/). 